\title{
Effect of additives on cutting temperature of glass fibers reinforced polymers
}

\author{
H. Kuate-Togue, J-F. Chatelain \\ Mechanical engineering department \\ École de technologie supérieure \\ Montréal, Canada \\ jean-francois.chatelain@etsmtl.ca
}

\author{
C. Ouellet-Plamondon \\ Construction engineering department \\ École de technologie supérieure \\ Montréal, Canada \\ claudiane.ouellet-plamondon@etsmtl.ca
}

\begin{abstract}
Composites are abrasive materials that generate heat during machining operations. This heat generates thermal damage locally and may severely alter the mechanical properties of the components if it exceeds the glass transition temperature of the matrix. This research studies the influence of additives, mixed to the epoxy matrix of Glass Fiber Reinforced Polymer (GFRP), on the cutting temperature. The results show that wax together with clay and a wetting agent, contribute to reduce the maximum cutting temperature, on a $300 \mathrm{~mm}$ length of cut, a value up to $28 \%$ as compared to a plain epoxy matrix.
\end{abstract}

Machining; temperature; GFRP; composite; additives

\section{INTRODUCTION}

The advanced industries such as the automotive, aerospace and wind industries are constantly innovating to improve the performance in terms of the weight and mechanical performance of their products. Traditionally used materials are metals that provide good mechanical performances. Metallic materials not only have good mechanical properties but are also relatively easy to machine. On the other hand, metals have a fairly high density, which implies high energy consumption by vehicles and mobile structures built with these materials. In order to reduce energy consumption, industries have introduced composite materials into the design and manufacture of mechanical parts. However, although these materials are mechanically efficient with a density that leads to reduced energy consumption, these materials have an abrasiveness that influences the temperature during machining operations.

The composite materials generally consist of a thermoset or thermoplastic matrix, and fibers as reinforcement elements. The most used and widespread fibers are carbon and glass mainly because of their mechanical and thermal properties. The use of composite materials in the manufacturing of parts or structures often requires cutting operations, like drilling, trimming or milling, before the assembly process [1]. However, these machining operations pose difficulties and quality issues because of their heterogeneity and anisotropic behavior as well as the abrasiveness of the fibers $[2,3]$.
The abrasiveness of the fibers alone is a cause of wear for the cutting tools. This wear is the source of a temperature increase which in turn provokes thermal damage on the cut surfaces and on the mechanical properties, specifically if the glass transition temperature ( $\mathrm{Tg}$ ) of the matrix is exceeded [46]. Previous studies showed that cutting temperature may reach values up to $450^{\circ} \mathrm{C}[7,8]$ during machining if tool wear is not properly controlled.

The tool wear do not only affect the temperature, but also the cutting forces. In fact, both phenomena are related, so that monitoring the forces may help to diagnose a worn tool $[6,8$, 9].

This research proposes to introduce additives or chemical components within the matrix as a solution to improve the machining process. The research aims to find additives that would allow a better interaction in the matrix-fiber contact surface in order to maintain good or improved mechanical performances [10-12], while reducing the temperature of cut which lead to better quality and lesser tool wear. The introduction of additives as a solution to reduce the cutting temperature was initially explored by Lasseur [5] study showing the performance of three additives. This paper will consider the study of five additives over a length of cut equal to $300 \mathrm{~mm}$.

\section{METHODOLOGY}

\section{A. Materials}

The material with which the experiments were made consists of long glass fibers with modified epoxy resin as matrix. The characteristics of the fibers and the resin are summarized in Table I.

TABLE I. CHARACTERISTICS OF THE FIBERS AND EPOXY RESIN

\begin{tabular}{|l|l|l|l|l|l|}
\hline Materials & Name & Company & $\begin{array}{c}\text { Density } \\
{\left[\mathbf{g} / \mathbf{c m}^{3}\right]}\end{array}$ & $\begin{array}{c}\text { Surface } \\
\mathbf{d e n s i t y} \\
{\left[\mathbf{g} / \mathbf{m}^{2}\right]}\end{array}$ & $\begin{array}{c}\text { Resin } \\
\text { viscosity } \\
{[\mathbf{P a . s}]}\end{array}$ \\
\hline Fibers & E-Glass & TEXONIC & 1,239 & 440 & - \\
\hline Resin & $\begin{array}{l}\text { Marine } \\
820\end{array}$ & ADTECH & 1,106 & - & 1,2 \\
\hline
\end{tabular}


Different laminate of $300 \mathrm{~mm}$ by $300 \mathrm{~mm}$ size were manufactured using the infusion method. A total of 16 unidirectional plies were stacked with a $45^{\circ}$ angle in order to have a trimming direction with respect to the fiber orientation of $-45^{\circ}$. This configuration is the worst one in terms of surface quality resulting from trimming operations. In fact, previous studies proved that such fiber orientation generates more delamination (uncut fibers and fiber pullout) and worst surface roughness than any other orientation with respect to the cutting direction [2, 13-16]. The thickness of all plaques manufactured with the various epoxy mixtures was controlled to be of $4.7 \mathrm{~mm}$, to ensure no variability in the results due to the fiber content. Five mixtures of epoxy were considered in this study considering three different additives with the following concentrations:

- Unmodified resin (RE)

- $\operatorname{Resin}+1 \%$ wt wetting agent (WA)

- $\operatorname{Resin}+1 \%$ wt WA $+1.5 \%$ wt clay (CL)

- $\operatorname{Resin}+1 \%$ wt WA + 2\% wt wax (WAX)

- $\operatorname{Resin}+1 \%$ wt WA $+1 \%$ wt WAX $+1 \%$ wt CL.

All mixtures were made according to the protocol proposed by Quaresimin, et al. [10], and Withers, et al. [11]. The characteristics and tradenames of the additives are summarized in table II. Based on these studies, as well as on the supplier technical documentation, these additives should play the following roles:

- The wetting agent, which is an antistatic, should allow diffusion, homogenization and stabilization of the additives in the mixture with the resin.

- The clay particles, which are particles having storage stability and sag resistance should improve the mechanical properties of the composite.

- The wax particles which have a low transition temperature $288.15 \mathrm{~K}\left(115^{\circ} \mathrm{C}\right)$ and low viscosity should therefore melt at the cutting surface during high temperature machining. It is expected to act as a lubricant to the cutting surface thus reducing the cutting temperature.

TABLE II. CHARACTERISTICS OF THE ADDITIVES

\begin{tabular}{|l|l|}
\hline \multicolumn{1}{|c|}{ Additives } & \multicolumn{1}{c|}{$\begin{array}{c}\text { Characteristics and } \\
\text { Supplier }\end{array}$} \\
\hline Wetting agent (WA) & BYK-W 972, BYK \\
\hline Clay particles (CL) & $\begin{array}{l}\text { Ømax }=59 \mu \mathrm{m} \text { GARAMITE- } \\
1958, \mathrm{BYK}\end{array}$ \\
\hline Wax particles (WAX) & $\begin{array}{l}\text { Ømax }=11 \mu \mathrm{m}, \mathrm{CERAFLOUR} \\
996, \mathrm{BYK}\end{array}$ \\
\hline
\end{tabular}

\section{B. Cutting temperature acquisition}

The temperature acquisition was done through two thermocouples welded symmetrically on diametrically opposed teeth of the cutting tool. The thermocouples are of type $\mathrm{K}$ having a diameter of $0.076 \mathrm{~mm}(0.003 ")$. The welded tip and the stripped thermocouples were covered with OmegaBond400 cement which has high thermal conductivity. Finally, the tip is covered with a J-B weld epoxy resin to reinforce the shear strength and prevent the weld from easily tearing during machining. In addition, it was determined experimentally that the distance between the cutting zone and the welded tip on the tool is $1.7 \mathrm{~mm}$ in order to avoid a detachment of the thermocouples due to the chip flow and temperature variation $[5,7]$. In addition, the closer are the thermocouples to the cutting zone, the more accurate will be the measurements [2, 9]. The cutting tool type is a CVD (Chemical Vapor Deposition) diamond coated having a $9.5 \mathrm{~mm}$ diameter with following characteristics:

TABLE III. CHARACTERISTICS OF THE CUTTING TOOL

\begin{tabular}{|l|l|l|}
\hline \multirow{4}{*}{ Machining Tool } & Material & Tungsten Carbide \\
\cline { 2 - 3 } & Coating material & Diamond \\
\cline { 2 - 3 } & Coating process & $\begin{array}{l}\text { Chemical Vapor Deposition } \\
(\text { CVD })\end{array}$ \\
\cline { 2 - 3 } & Diameter & $9.5 \mathrm{~mm}\left(3 / 8^{\prime \prime}\right)$ \\
\cline { 2 - 3 } & Number of teeth & 6 \\
\cline { 2 - 3 } & Helix angle & $10^{\circ}$ \\
\hline
\end{tabular}

The tool instrumented with thermocouples is mounted in a holder equipped with a wireless transmission system on which the red-AL (aluminum) and yellow-CR (chromium) pairs of wires are connected to transmit the signal during the cutting process (fig. 1). The cutting operations were performed using a 3-axis Huron K2X10 CNC machine having a maximum speed of $28000 \mathrm{RPM}$ and power of $40 \mathrm{~kW}$. Not only the temperature data was recorded, but also the cutting forces through a Kistler 9255B dynamometric table, as shown in figure 2 . The forces data will help to understand the first contact between the tool and the laminate.

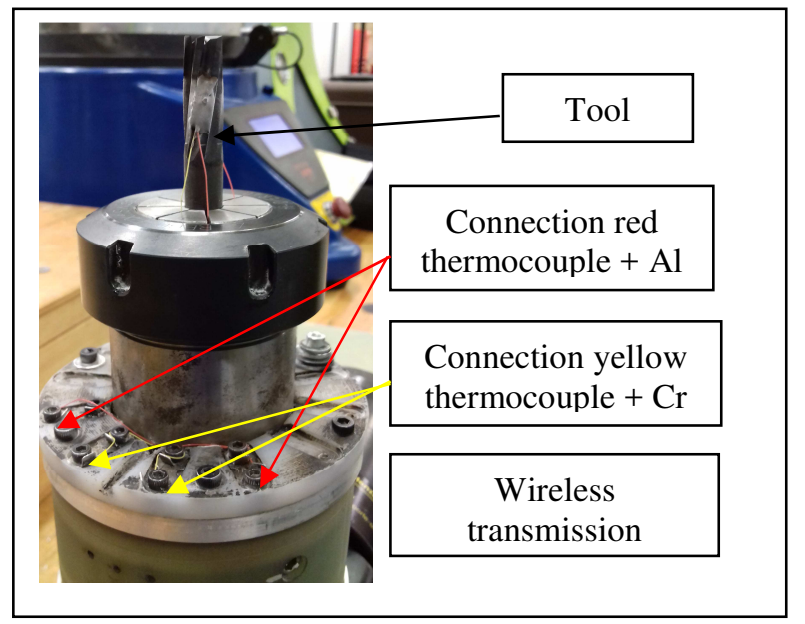

Figure 1. Tool mounting on the spindle 


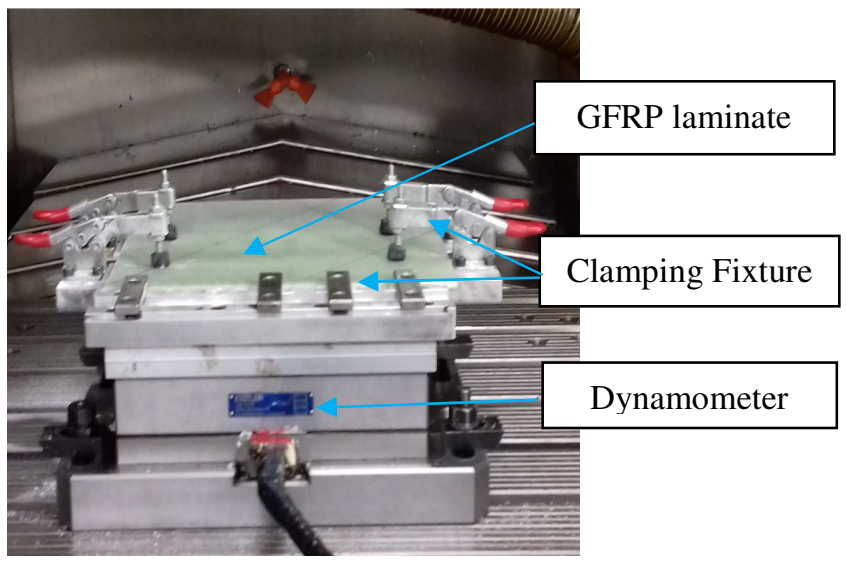

Figure 2. Experimental cutting configuration

With the objective of observing the influence of additives on the cutting temperature, the cutting parameters were fixed constant. The maximum allowed rotational speed of the wireless telemetry system used for temperature acquisition being $10000 \mathrm{RPM}$, the cutting speed of the laminates was fixed to $300 \mathrm{~m} / \mathrm{min}$. Regarding the feed rate, based on previous experiments, it was fixed to $1140 \mathrm{~mm} / \mathrm{min}(0.0190 \mathrm{~mm} /$ tooth $)$. The cutting operation was carried out over a distance of 300 $\mathrm{mm}$.

\section{RESULTS AND DISCUSSION}

The cutting operations for the different laminates started at room temperature, which corresponds $20{ }^{\circ} \mathrm{C}$. The figure 3 shows the temperature along a cutting distance of $300 \mathrm{~mm}$ for all types of laminate. It can be noted that the laminates containing the WA, the WA-WAX, and the WA-WAX-CL have a lower cutting temperature than the reference laminate containing only the epoxy resin (RE). In contrast, only the cutting temperature for the WA-CL laminate is higher than that of the reference laminate. Focusing on the laminates containing respectively WA-CL, WA, WA-WAX, one could validate how the wax plays a beneficial role of lubricating after a certain cutting temperature. The curves start almost from the same point and they are close to each other over a distance of $20 \mathrm{~mm}$. Afterwards, we observe that the WA-CL and WA-WAX-CL curves are visibly off the other three curves. From this result, one may conclude of a combinatory phenomenon between the clay and the wax which favors a reduction of the cutting temperature. However, more study is further required to confirm this hypothesis, since the standard deviation of the temperature differences remains large for some mixtures as shown in Figure 4.

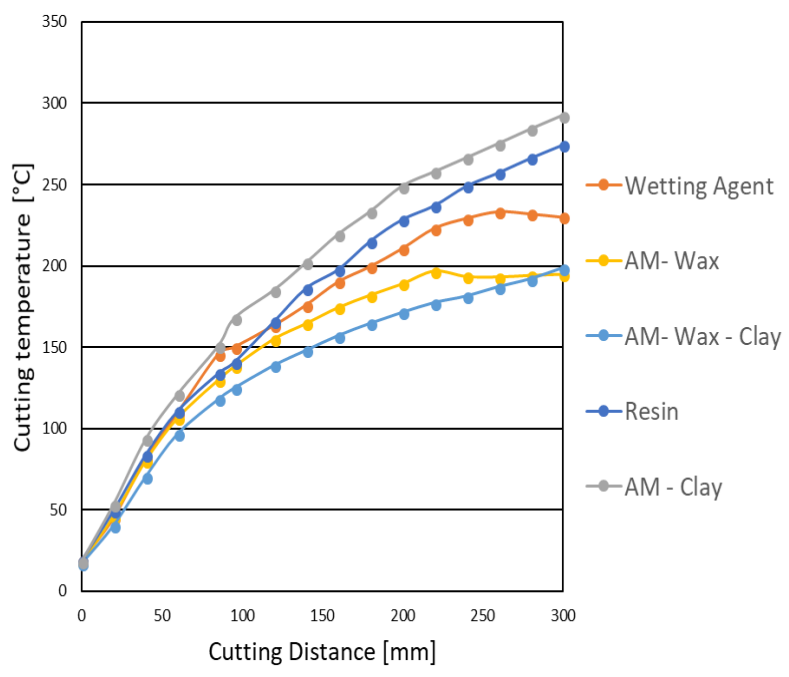

Figure 3. Cutting temperature over a distance of $300 \mathrm{~mm}$.

Evaluating the average temperature differences (Figure 4) relative to the reference temperature which is that of the unmodified resin, it can be noted as expected that the average temperature difference is positive only for the laminate WACL. However, the values of the average temperature difference are significant over a cutting distance of $300 \mathrm{~mm}$, unlike those obtained by Lasseur [5] over a reduced distance of $100 \mathrm{~m}$. The negative values of the average temperature differences observed for the WA, WA-WAX, WA-WAX-CL laminates reflect a reduction in cutting temperature compared to the reference (Resin). Figure 4 also shows standard deviations of the temperature differences. It is observed, however, that the range of standard deviations obtained with the WA-WAX and WA-WAX-CL laminates does not intercept the reference axis as opposed to the gap obtained with the WA laminate. Hence, the wetting agent (WA), alone, would not be appropriate to reduce the cutting temperature. The addition of the clay to the wetting agent would involve an increase in cutting temperature. The figure 5 shows the maximum temperature values achieved for each laminate. The graph reflects the analysis mentioned above. In addition, from this figure, we observe that the laminates containing WA-WAX and WA-WAX-CL are those that actually lead to a reduction of the cutting temperature by taking into account the standard deviations of the temperature differences. Thus, there is a decrease of respectively $28.7 \%$ and $26.5 \%$ in the cutting temperature. 


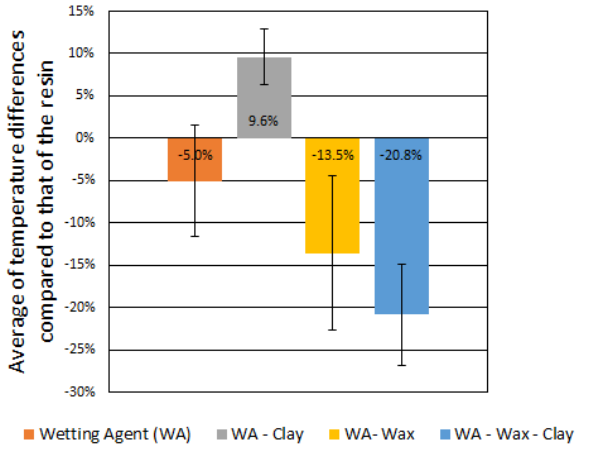

Figure 4. Average of temperature differences compared to that of the resin over a distance of $300 \mathrm{~mm}$.

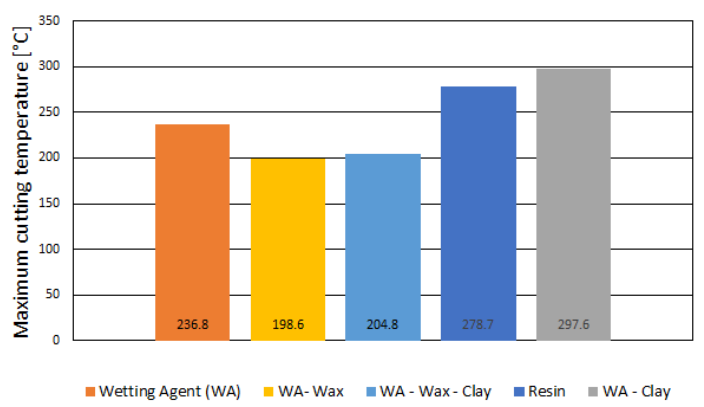

Figure 5. Maximum cutting temperature over a distance of $300 \mathrm{~mm}$.

\section{CONCLUSION}

The objective of this work was to study the influence of additives on the cutting temperature of GFRP laminates. It is apparent that the cutting temperature of the laminates made from WA-CL additives to the epoxy generates higher cutting temperature. Addition of wax to the epoxy clearly lowers the cutting temperature. The best mixture found was the WAWAX-CL with a maximum temperature decrease up to $28 \%$. Further development will focus on the effect of these mixtures on the mechanical properties of the GFRP composite.

\section{REFERENCES}

[1] B. L. B. Furet, Benoît, "Milling and drilling of composite materials for the aeronautics: feature aeronautics," JEC Magazine \#18, June-July 2005 2005.

[2] M. H. El-Hofy, S. L. Soo, D. K. Aspinwall, W. M. Sim, D. Pearson, and P. Harden, "Factors Affecting Workpiece Surface Integrity in Slotting of CFRP," Procedia Engineering, vol. 19, pp. 94-99, 2011/01/01/ 2011.
[3] J. P. Davim and P. Reis, "Damage and dimensional precision on milling carbon fiber-reinforced plastics using design experiments," Journal of Materials Processing Technology, vol. 160, no. 2, pp. 160-167, 2005/03/20/ 2005.

[4] K.-M. Li, C. Wang, and W.-Y. Chu, "An improved remote sensing technique for estimating tool-chip interface temperatures in turning," Journal of Materials Processing Technology, vol. 213, no. 10, pp. 17721781, 2013/10/01/ 2013.

[5] B. Lasseur, "Étude de l'effet d'additifs sur la qualité de la coupe et les performances mécaniques d'un matériau composite," École de technologie supérieure, 2017.

[6] J. Delahaigue, J.-F. Chatelain, and G. Lebrun, "Influence of Cutting Temperature on the Tensile Strength of a Carbon Fiber-Reinforced Polymer," Fibers, vol. 5, no. 4, 2017.

[7] M. J. F. Guillaume, Chatelain, "Influence of Thermal Damage on the Mechanical Strength of Trimmed CFRP," International Journal of Mechanical, Aerospace, Industrial, Mechatronic and Manufacturing Engineering, vol. 9, pp. 1558-1566, 9/ 2015.

[8] H. Hamedanianpour, Effect to tool wear on quality of carbon fiber reinforced polymer laminate during edge trimming (Mgm, no. 2013:21]). Montréal: École de technologie supérieure, 2013, pp. 1 ressource en ligne (xviii, 143 pages).

[9] R. Teti, K. Jemielniak, G. O'Donnell, and D. Dornfeld, "Advanced monitoring of machining operations," CIRP Annals, vol. 59, no. 2, pp. 717-739, 2010/01/01/2010.

[10] M. Quaresimin, M. Salviato, and M. Zappalorto, "Fracture and interlaminar properties of clay-modified epoxies and their glass reinforced laminates," Engineering Fracture Mechanics, vol. 81, pp. 8093, 2012/02/01/ 2012.

[11] G. J. Withers et al., "Improved mechanical properties of an epoxy glassfiber composite reinforced with surface organomodified nanoclays," Composites Part B: Engineering, vol. 72, pp. 175-182, 2015/04/01/ 2015.

[12] S. Gurusideswar and R. Velmurugan, "Strain rate sensitivity of glass/epoxy composites with nanofillers," Materials \& Design, vol. 60, pp. 468-478, 2014/08/01/ 2014.

[13] O. Pecat, R. Rentsch, and E. Brinksmeier, "Influence of Milling Process Parameters on the Surface Integrity of CFRP," Procedia CIRP, vol. 1, pp. 466-470, 2012/01/01/ 2012.

[14] T. Rajasekaran, B. K. Vinayagam, K. Palanikumar, and S. Prakash, "Influence of machining parameters on surface roughness and material removal rate in machining carbon fiber reinforced polymer material," in Frontiers in Automobile and Mechanical Engineering -2010, 2010, pp. 75-80.

[15] M. Ramulu, "Machining and surface integrity of fibre-reinforced plastic composites," Sadhana, vol. 22, no. 3, pp. 449-472, 1997/06/01 1997.

[16] J. F. Chatelain, Z. Imed, and M. Joseph, "Effect of Ply Orientation on Roughness for the Trimming Process of CFRP Laminates," International Journal of Mechanical, Aerospace, Industrial, Mechatronic and Manufacturing Engineering, vol. 6, pp. 1515-1522, 9/ 2012. 